\title{
Erratum to: The succession process in Chinese family firms: A guanxi perspective
}

\section{Junsheng Dou • Shengxiao Li}

Published online: 12 September 2012

(C) Springer Science+Business Media, LLC 2012

\section{Erratum to: Asia Pac J Manag \\ DOI 10.1007/s10490-012-9287-7}

We would like to clarify that the grant number of National Natural Science Foundation of China should be 70902057; the number used before is wrong.

The online version of the original article can be found at http://dx.doi.org/10.1007/s10490-012-9287-7.

\section{J. Dou $(\bowtie)$}

School of Management, Zhejiang University, PO Box 1512, Hangzhou 310027, China e-mail: jsdou@zju.edu.cn

S. $\mathrm{Li}$

College of Business and Management, Shaoxing University, Shaoxing 312000, China e-mail: 1sx_3100@163.com 